\title{
IMPROVING THE EFFICIENCY OF THE UNIT OF THE ZAPORIZHZHIA NPP WITH A WWER-1000 REACTOR
}

\author{
A.A. Cheilytko, A.V. Karpenko, S.V. Ilin \\ Zaporizhzhia National University, Zaporizhzhia, Ukraine \\ E-mail: abkarpenko_77@meta.ua
}

\begin{abstract}
Improving the efficiency of the unit of the Zaporizhzhia NPP with a WWER-1000 reactor, by reducing the water temperature at the inlet to the condenser. The work describes the description of the NPP and the nuclear power reactor WWER-1000, by reducing the water temperature at the inlet to the condenser. Detailed neutron-physical calculation of the nuclear power unit with WWER-1000 reactor with a turbine installation K-1000-60/3000. The influence of the temperature of cooling water on the input to the capacitor and the load on the efficiency of the turbine installation and the flow of steam and heat to the turbine installation is established.
\end{abstract}

\section{INTRODUCTION}

The scale of production and use of fossil energy for the production of the required amount of energy for humanity is enormous, and resources are limited. The problem of rapid depletion of organic natural resources of Ukraine is particularly acute. The use and development of nuclear energy, also the improvement of its efficiency, reduce the severity of this problem.

In 1977, due to the growing problem of power south of the country, the Council of Ministers decided to build Central Ukrainian nuclear power plant. After technical and economic characteristics analyzing of the nuclear power station placing alternative points USSR Ministry of Energy chose the item "Zaporizhzhya" 40 years have passed and in 2017 the Zaporizhzhya Nuclear Power Plant (ZNPP) fulfilled its target of 33 billion 20 million $\mathrm{kW} \cdot \mathrm{h}[1]$.

The bulk of any nuclear reactor is the core in which the fission chain reaction takes place. It is formed by loaded nuclear fuel in the form of fuel elements - fuel rods. Drill diameter $9.1 \mathrm{~mm}$, fuel pellet diameter $7.53 \mathrm{~mm}$, loading weight of fuel rod uranium dioxide $1565 \mathrm{~g}$. Fuel rods are combined into cassette-type fuel assemblies containing 317 fuel rods and 12 directional control rods. Number of fuel assemblies in the core 163 of them with control rods -61 . The heat released by fuel rods, given continuously circulates coolant. At the ZNPP with the WWER-1000 reactor (water-water power reactor), unlike the Chernobyl station with RBMK type reactors, the use of core heat is carried out by a two-circuit scheme.

The ZNPP is connected to the unified power system of Ukraine through three $750 \mathrm{kV}$ transmission lines and one $330 \mathrm{kV}$ AC line.

Today, there are four NPPs operating in Ukraine, with 15 WWER generating units with a total capacity of 13880 MW. Over the last decade, the total annual electricity production in Ukraine has increased, and the share of energy production at nuclear power plants has increased. That is, nuclear energy has become a major stabilizing factor in the state's energy system. These facts, as well as the analysis of the energy needs of the state and the possibilities of their satisfaction, testify to the expediency and necessity of the development of nuclear energy in Ukraine. Choosing exactly this path is in line with the global trend [2-4].
The successful operation of nuclear power - one of the necessary conditions to ensure national security.

\section{AIMS AND OBJECTIVES}

The object of study - ZNPP unit with the WWER1000 reactor.

Subject of study - nuclear reactor of ZNPP and its geometric characteristics.

Purpose of the work - analyze the impact of changes in water temperature turbine condenser entrance to the performance of the NPP Unit.

Research objectives. To achieve this goal in the following problems solved:

- analysis of the literature about research;

- performing of neutron-physical and thermalhydraulic calculations of a nuclear power unit with a WWER-1000 reactor with turbine K-1000-60/3000;

- influence of the cooling water temperature at the inlet of the condenser and the load on the turbine unit efficiency and steam and heat consumption for the turbine unit;

- conduct a study of the influence of parameters intermediate overheating steam on the efficiency of the unit.

Research methods and means. The tasks were solved by calculating of the nuclear reactor and analyzing the effect of water temperature changing at the inlet of the condenser of the turbine. The paper used basic theoretical concepts for nuclear energy released by a nuclear chain reaction fission of uranium or plutonium.

The practical value of the work is as follows influence of the cooling water temperature at the inlet of the condenser and the load on the turbine unit efficiency and steam and heat consumption for the turbine unit was established.

\section{ANALYSIS OF THE LITERATURE ABOUT RESEARCH}

Increasing the amount of energy absorbed in the second circuit of the NPP is considered by many authors. Thus, the intensification of heat and mass transfer in NPP steam generators is considered in [5]. Second circuit auxiliaries with a hydrogen plant were considered in [6], but heightening the isoentropic turbine heat transfer is the best method for increasing the efficiency of the NPP unit with WWER reactors [7]. An increase in isoentropic heat transfer is possible by 
changing either the initial or final steam parameters, or by using an intermediate superheat with steam separation. Reducing the final steam parameters in a condenser by reducing the cooling water temperature is the simplest solution. The issue of cooling water in the condenser is discussed in Refs. [8-10].

A very important factor in the efficiency calculation is a complex technical and economic evaluation of the implemented measures regarding implementation stages term perspective [11].

\section{INTERMEDIATE STEAM OVERHEATING ORGANIZATION SCHEME AT NPP}

In a thermal power installation with intermediate steam overheating, steam after expansion in the high pressure cylinder (HPC) of the turbine, is sent to a reactor for secondary overheating, where its temperature rises to almost the same level as before the HPC. After an intermediate overheating, the steam is sent to a lowpressure cylinder, where it expands to the pressure in the condenser.

The efficiency of an ideal thermal cycle with intermediate overheating depends on the parameters of the steam that is relegated to intermediate overheating. The optimum vapor temperature at which it must be vented to intermediate overheating can be estimated as $1.02 \ldots 1.04$ from the feedwater temperature.

The steam pressure before the intermediate overheating is usually chosen to be $0.15 \ldots 0.30$ fresh steam pressure. As a result of the intermediate overheating, the overall cycle economy increases. However, due to the decrease in steam humidity in the last stages of the low-pressure turbine, the relative internal efficiency of these stages will increase, and accordingly, the efficiency of the entire turbine will increase.

The loss of pressure in the path of intermediate overheating (in the steam line from the turbine to the boiler, superheater and steam line from the boiler to the turbine) reduces the effect of the application of intermediate overheating of steam and therefore allowed no more than $10 \%$ loss of absolute pressure in the intermediate superheater.

In a double-circuit scheme of a nuclear power plant with secondary steam overheating in a nuclear reactor (Fig. 1), the working fluid (steam) enters the second group of reactor operating channels after the surface steam generator, where its overheating is carried out, and then into the turbine.

In this case, the parameters of the working fluid in front of the turbine are increased, which leads to an increase in the thermal efficiency of the nuclear power plant central (NPPC). However, under this scheme of NPPC also the radioactive hazard in the second circuit are increasing. This scheme arose from the refusal of overheating of steam (working fluid) in a separate surface steamheater, resulting in the pressure and temperature of the coolant (also steam) in the first circuit would be unacceptably high for the metal shells of the fuel elements.

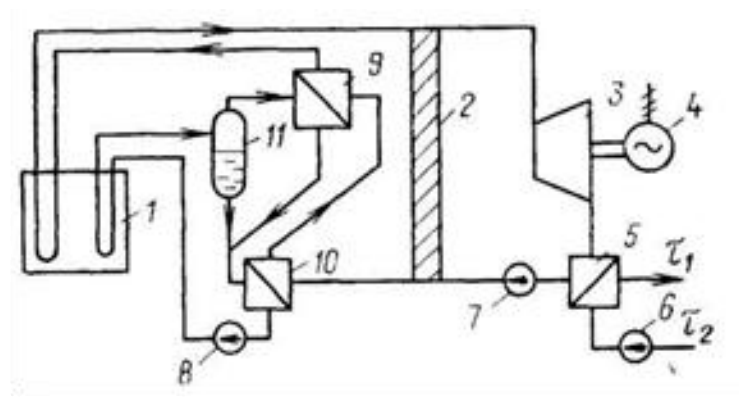

Fig. 1. Schematic diagram of a two-circuit NPP with secondary steam overheating in a nuclear reactor:

1 - nuclear reactor; 2 - biological protection; 3 -turbine; 4 -electric generator; 5 -district heating heater; 6-mains pump; 7 -feed pump; 8-circulation pump; 9 -surface steam generator; 10 -economizer; 11 - evaporator drum

Regeneration has a positive effect on the relative internal efficiency of the first stages due to the increased steam flow through the HPC and the corresponding increase in the height of the blades. The volumetric flow of steam through the last stages of the turbine during regeneration is reduced, which reduces the losses with the output speed in the last stages of the turbine.

\section{THE THERMODYNAMIC CYCLE OF SEPARATION AND INTERMEDIATE OVERHEATING}

Steam, which has reached the maximum permissible values of humidity, after the main cylinder of the turbine is taken to a special separator and dried in it at constant pressure (temperature) - line fd (Fig. 2).

At the same time useful work increases by the size of the area f 'fdd'. After the separation of moisture, it is possible to carry out an intermediate overheating of the steam due to the condensation of a part of the initial parameters. This allows for the further expansion of steam in the turbine to ensure in its last stages the allowable steam humidity.

Overheating is held in surface heat exchanger, and therefore the final temperature of the intermediate overheating will be lower than the initial temperature.

From Fig. 2 we see that the intermediate steam separation increases the useful work by the size of the area f 'fdd', but at the same time increases (and more significantly) the heat dissipation in the cold source area f "f ' $d$ ' $d$ ".

Similar effect and intermediate overheating, since the area d'dee', corresponding to the growth of useful work, is smaller than the area d"d'e'e"corresponding to an increase in heat dissipation in a cold source.

Thus, the efficiency of the cycle with intermediate separation and superheating steam is less than for the cycle without intermediate separation and superheating steam due to the fact that the implementation of the cycle without separation and overheating at a pressure in a cold source of $0.005 \mathrm{MPa}$ is impossible. Therefore, direct comparison is inappropriate. The cycle with separation and intermediate overheating must be compared with the cycle in the absence of them with a permissible ultimate humidity. Then the cycle without 
separation will have a pressure in the cold source substantially higher than $0.005 \mathrm{MPa}$.

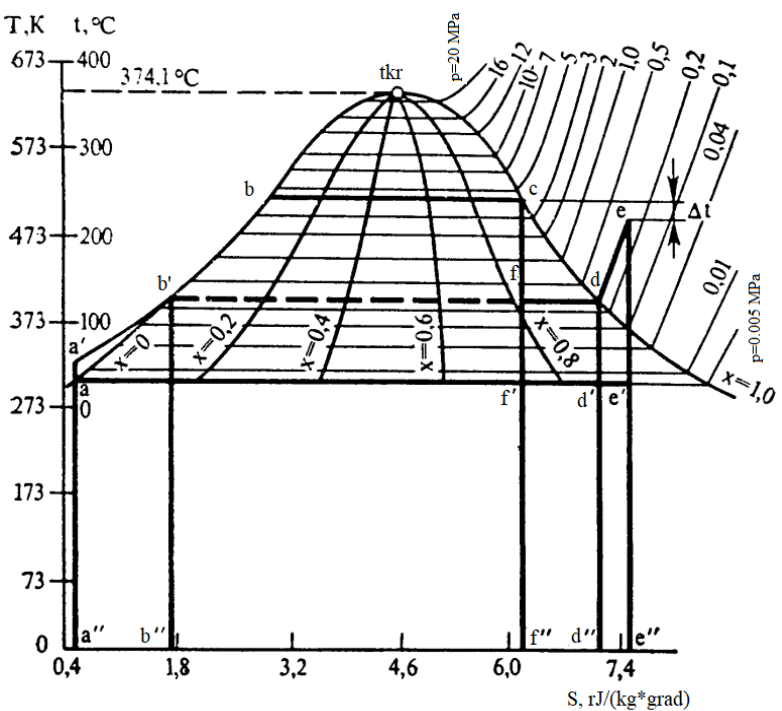

Fig. 2. Ideal thermodynamic cycle with separation and intermediate overheating of steam turbine of NPP with a water coolant

Useful work in this case will be equal to the area b'bcf, allotment in a cold source - area b"b'ff", and the efficiency of such a cycle will correspond to the ratio of the area b'bcf and b'b'ff", i. e. it will be significantly lower than at intermediate separations and steam overheating.

The actual process in the h, s-diagram (Fig. 3) shows that the separation and intermediate overheating of the steam after the high-pressure cylinder allow more than twice to increase the existing adiabatic heat differential. And the increase in the work done per kilogram of steam makes it possible to reduce the steam flow per turbine at the same capacity accordingly. This makes it easier to design for large capacities. In other words, intermediate separation and overheating make it possible to design turbines of considerable capacity even for medium parameters.

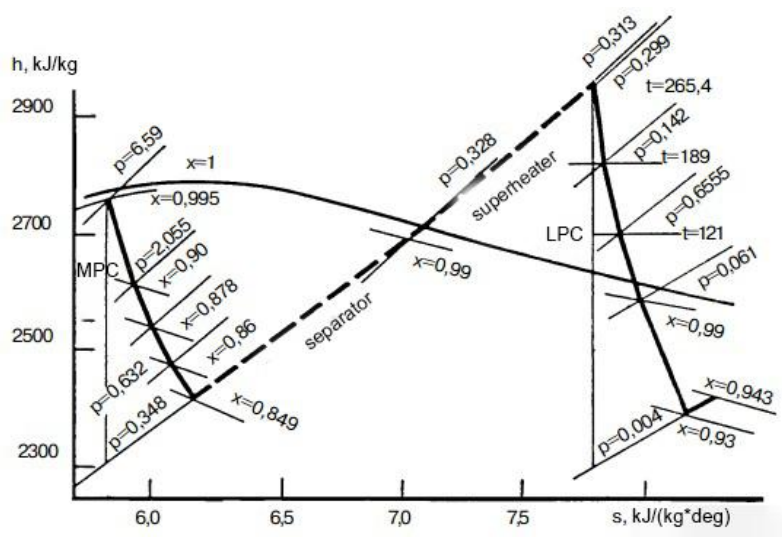

Fig. 3. Real process in a steam turbine installation on saturated steam in the hs-diagram with intermediate separation and overheating

\section{KEY ANALYTICAL STUDIES ON THE EFFECTS OF COOLING WATER TEMPERATURE AT THE INLET OF THE CONDENSER}

A geometric calculation and a thermal-hydraulic calculation of the reactor were performed [12]. The variation of the temperature of the inner and outer surfaces of the fuel core by the height of the reactor and in the radial direction at average (a) and maximum (b) loading is shown in Fig. 4.

The thermal scheme of the K-1000-60/3000 turbine at full and partial loads and different cooling water temperature at the inlet of the condenser is also calculated.

Lowering the temperature of the cooling water at the inlet of the condenser leads to an increase in the average temperature difference of supply and heat dissipation, the available heat transfer and the thermal efficiency of the cycle.
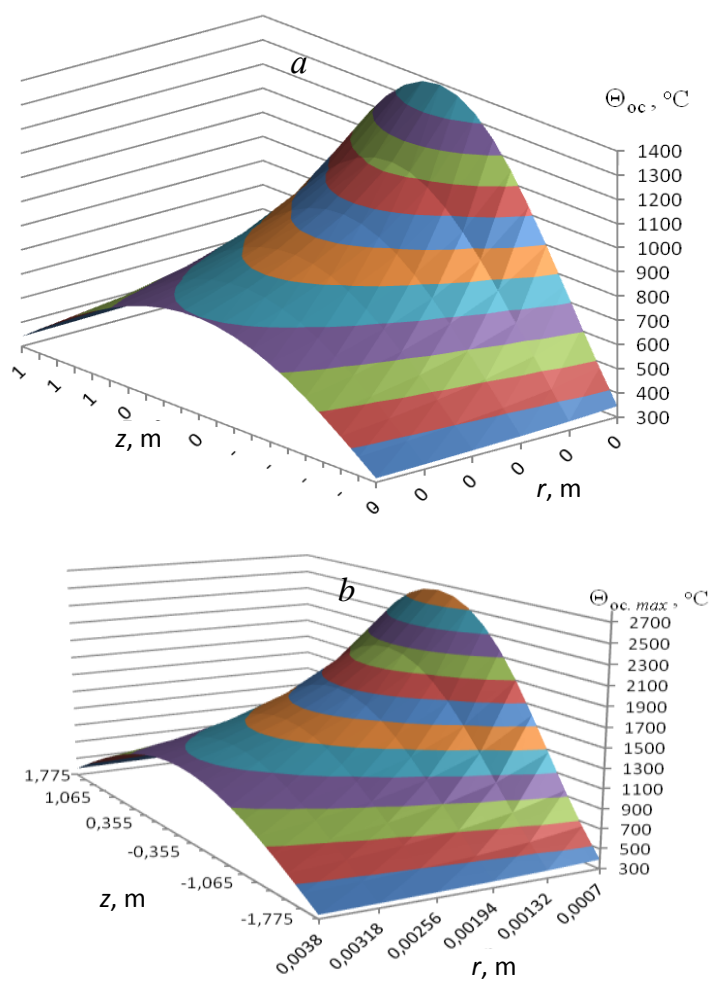

Fig. 4. Temperature changing of the inner and outer surfaces of the fuel core by the height of the reactor and in the radial direction at medium (a) and maximum (b) loads

Thus, the main performance of the unit at different capacities was calculated. It was established that the value of turbine efficiency increases linearly with decreasing temperature of the cooling water and is almost independent of the load. Fresh steam and heat consumption at the turbine unit decrease by lowering the cooling water temperature at the inlet of the condenser and reducing the load on the turbine unit (Table). 
Performance of the unit at rated power

\begin{tabular}{|c|c|c|c|c|}
\hline $\begin{array}{c}\mathrm{t}_{\text {cool.wat. }}, \\
{ }^{\circ} \mathrm{C}\end{array}$ & Gross & Net & $\mathrm{D}_{0}, \mathrm{~kg} / \mathrm{h}$ & $\mathrm{Q}, \mathrm{kW} / \mathrm{h}$ \\
\hline 10 & 0.3762 & 0.3744 & 5603147.5 & 10239466302 \\
\hline 12 & 0.3728 & 0.3710 & 5653581.6 & 10331632048 \\
\hline 14 & 0.3699 & 0.3681 & 5698049.7 & 10412895309 \\
\hline 16 & 0.3673 & 0.3655 & 5738284.6 & 10486422481 \\
\hline 18 & 0.3642 & 0.3624 & 5786902.5 & 10575269162 \\
\hline 20 & 0.3618 & 0.3599 & 5826827.4 & 10648229841 \\
\hline 22 & 0.3589 & 0.3571 & 5873502.1 & 10733525479 \\
\hline 24 & 0.3554 & 0.3536 & 5930754.7 & 10838151709 \\
\hline 26 & 0.3523 & 0.3505 & 5982529.4 & 10932767280 \\
\hline 28 & 0.3496 & 0.3478 & 6029275.6 & 11018193752 \\
\hline 30 & 0.3471 & 0.3453 & 6072718.7 & 11097583665 \\
\hline
\end{tabular}

Changing the load changes consumption of fresh steam and steam flow at all areas HPC.

The graphical dependences of the power unit performance while changing the load and the temperature of the cooling water at the inlet of the condenser are shown in Figs. 5, 6.

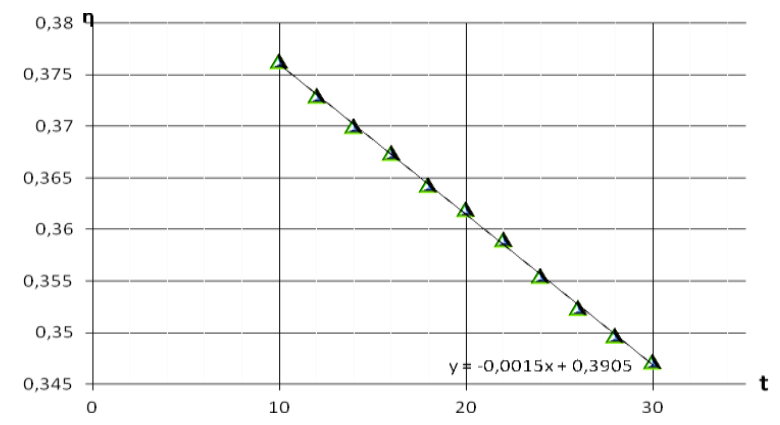

Fig. 5. Dependence of gross efficiency from the load and temperature of cooling water at the inlet of the condenser

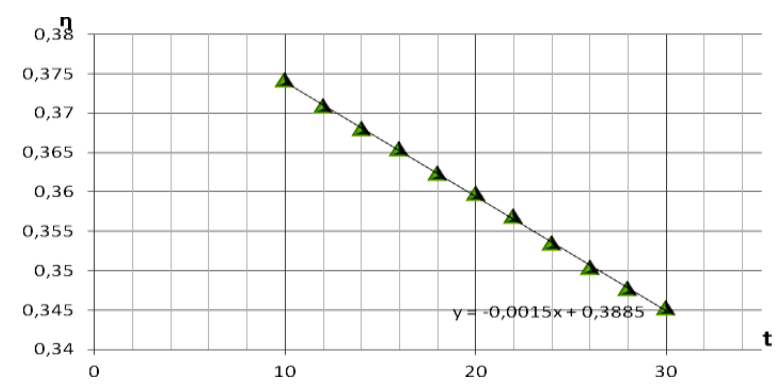

Fig. 6. Dependence of net efficiency from the load and temperature of cooling water at the inlet of the condenser

The dependence of the turbine unit efficiency at lowering the cooling water temperature was found by the least squares' method.

For gross efficiency:

$$
\eta_{\mathrm{b}}=-0.0015 \cdot \mathrm{t}+0.3905
$$

for net efficiency:

$$
\eta_{\mathrm{n}}=-0.0015 \cdot \mathrm{t}+0.3885
$$

The average monthly water temperature of the NPP basin in July is $+22^{\circ}$. The conditional electricity consumption for water cooling at the inlet of the condenser in July is $58223416 \mathrm{~kW} / \mathrm{h}$. Therefore, cooling the water at the inlet of the condenser significantly increases the efficiency of the ZNPP unit.

Consider the dependence of fresh steam consumption and heat from the load and the temperature of the cooling water at the inlet of the condenser (Figs. 7, 8).

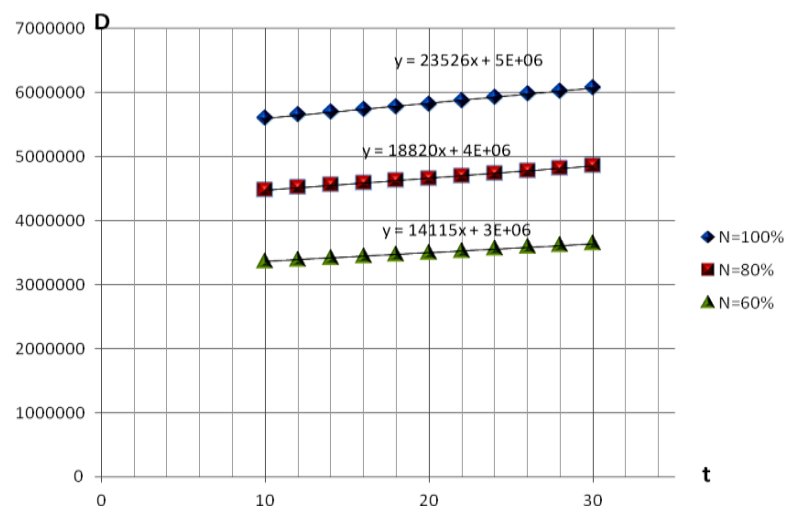

Fig. 7. Dependence consumption of fresh steam from the load and temperature of cooling water at the inlet of the condenser

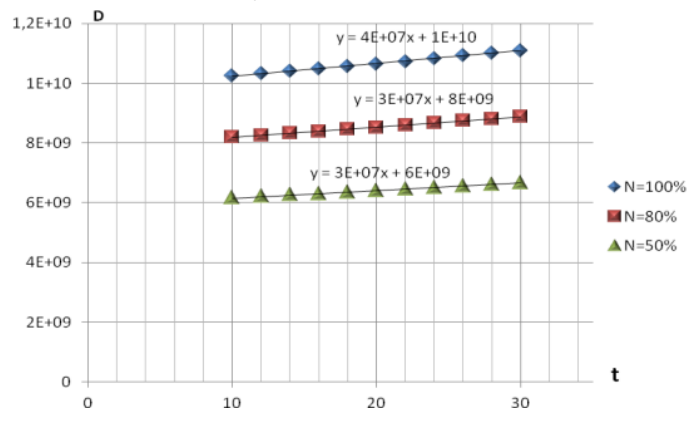

Fig. 8. Dependence of heat consumption from the load and temperature of cooling water at the inlet of the condenser

By lowering the cooling water temperature at the inlet to the condenser and reducing the load on the turbo unit, the fresh steam and the heat consumption at the turbine unit decrease.

\section{CONCLUSIONS}

The thermal calculation of the second circuit of the nuclear power unit with the WWER-1000 reactor and the K-1000-60/3000 turbine unit was performed. As a result of the calculation, the parameters of steam, water and condensate were determined at all points of the thermal scheme, high values of efficiency were established, which testifies to the efficiency of the turbine installation. In determining the cost-effectiveness of the installation, the total electrical efficiency (gross) of the turbine unit was calculated, which is 0.3426 and the efficiency of the pump driven (net) electricity, which is 0.3408 , the unit efficiency is 0.3324 , the specific fuel consumption is $0.16245 \mathrm{~g} /(\mathrm{MW} \cdot \mathrm{h})$.

Thermal-hydraulic, geometrical calculations of the fuel and energy center and the neutron-physical calculation of the reactor were carried out. As a result, a 
number of graphical dependencies were obtained, which allow to establish the change of the coolant pressure and the heat load along the height of the reactor core; change in the temperatures of the coolant, the outer surface of the fuel rod and the saturation temperature along the height of the reactor core for different loads; a change in the temperature of the fuel core in the radial direction for the central plane of the core and a change in the temperature of the inner and outer surfaces of the fuel core along the height of the reactor core; change of heat flow per unit surface of fuel rod and enthalpy of coolant and enthalpy of saturation by height of the core; change in critical heat flux and stock to the boiling point of the reactor core.

By the least-squares method was found the dependence of the turbine unit efficiency at lowering the cooling water temperature. The average monthly water temperature of the NPP basin in July is $+22^{\circ}$. The conditional electricity consumption for cooling the water at the inlet of the condenser in July is $58223416 \mathrm{~kW} / \mathrm{h}$, which compensates for the increase in NPP efficiency. Therefore, cooling the water at the inlet of the condenser significantly increases the efficiency of the ZNPP unit and is economically feasible.

\section{REFERENCES}

1. Nuclear Power [Electronic resource] // South Ukrainian NPP - Access mode: URL: https://www.sunpp.mk.ua/en/nuclear. Official site of South - Ukrainian power complex.

2. Official site of ZNPP [Electronic resource] // Zaporizhzhya nuclear power plant. Access mode: URL: http://www.npp.zp.ua - Official site of ZNPP.

3. Report on the State of Nuclear and Radiation Safety in Ukraine in 2012 [Text] // State committee of nuclear regulation of Ukraine. 2012.

4. T. Ianko, S. Panov, O. Sushchyns'ky, M. Pylypenko, O. Dmytrenko. Zirconium alloy powders for manufacture of 3D printed articles used in nuclear power industry // Problems of Atomic Science and Technology. 2018, N 1(113), p. 148-153.

5. N.D. Agafonova, M.Yu. Egorov, V.V. Sergeev, et al. Heat-and-mass transfer intensification in saturatedsteam generators in NPP with VVER as a means for Increasing efficiency and reliability // Atomic Energy. 2018, v. 123, N 3, p. 154158.

6. R.Z. Aminov, A.N. Bairamov. Participation efficiency of the NPP with the hydrogen production facility in primary frequency regulation of the power system // Journal of Physics: Conference Series. 2018, v. 1111, N 1, p. 1-9.

7. Rauf Terzi, Erol Kurt. Improving the efficiency of a nuclear power plant using a thermoelectric cogeneration system // International Journal of Renewable Energy Development Open Access Copyright. 2018, v. 7, N 1, p. 77-84.

8. S. Huang, W. Zuo, M. Sohn. Improved cooling tower control of legacy chiller plants by optimizing the condenser water set point // Building and Environment. 2017, v. 111, p. 33-46.

9. Rafał Laskowski. Relations for steam power plant condenser performance in off-design conditions in the function of inlet parameters and those relevant in reference conditions // Applied Thermal Engineering. 2016, v. 103, p. 528-536.

10. Yea-Kuang Chan, Yu-Ching Tsai. Power uprate operation at Chinshan Nuclear Power Station // Nuclear Engineering and Design. 2019, v. 343, p. 96-102.

11. V.S. Krasnorutsky, O.S. Kirsanova. On variants of the nuclear fuel cycle of Ukraine // Problems of Atomic Science and Technology. 2019, N 2(120), p. 7481 .

12. V.A. Kiriyachenko, V.N. Petrykin, B.L. Pilipchik, et al. Fundamentals of the theory and design of nuclear power plants of nuclear power plants. Sevastopol: SNUAEiP, 2011, 480 p.

Статья поступила в редакциию 07.08.2019 2.

\section{ПОВЫШЕНИЕ ЭФФЕКТИВНОСТИ РАБОТЫ БЛОКА ЗАПОРОЖСКОЙ АЭС С РЕАКТОРОМ ВВЭР-1000}

\section{А.А. Чейлитко, А.В. Карпенко, С.В. Ильин}

Эффективность работы блока Запорожской АЭС с реактором ВВЭР-1000 возможно повысить в результате уменьшения температуры воды на входе в конденсатор. Приведено описание работы АЭС и ядерного энергетического реактора ВВЭР-1000. Выполнен детальный нейтронно-физический расчет ядерного энергоблока с реактором ВВЭР-1000 турбоустановки К-1000-60/3000. Установлено влияние температуры охлаждающей воды на КПД, расход пара и теплоту турбоустановки.

\section{ПІДВИЩЕННЯ ЕФЕКТИВНОСТІ РОБОТИ БЛОКУ ЗАПОРІЗЬКОЇ АЕС 3 РЕАКТОРОМ ВВЕР-1000}

\section{А.О. Чейлитко, Г.В. Карпенко, С.В. Ільйн}

Ефективність роботи блоку Запорізької АЕС з реактором ВВЕР-1000 шляхом зменшення температури води на вході в конденсатор. Наведено опис АЕС та ядерного енергетичного реактора ВВЕР-1000. Виконано детальний нейтронно-фізичний розрахунок ядерного енергоблоку 3 реактором $\mathrm{BBEP}-1000 \quad 3$ турбоустановкою К-1000-60/3000. Встановлено вплив температури охолоджуючої води на ККД, витрату пари і теплоти на турбоустановки. 